\title{
TEORIAS DA EDUCAÇÃO E FORMAÇÃO DO EDUCADOR: CONTRA O ESVAZIAMENTO DO CONTEÚDO E A FAVOR DE UMA PRÁXIS REVOLUCIONÁRIA
}

\author{
TEORÍAS DE LA EDUCACIÓN Y FORMATION DEL EDUCADOR: CONTRA EL \\ VACIAMIENTO DE CONTENIDO Y EN FAVOR DE UNA PRAXIS \\ REVOLUCIONARIA
}

\author{
THEORIES OF EDUCATION AND EDUCATOR'S TRAINING: AGAINST THE \\ EMPTYING OF ITS CONTENT AND IN FAVOR OF A REVOLUTIONARY PRAXIS
}

\author{
Ruth de PAULA ${ }^{1}$ \\ Betanea MORAES ${ }^{2}$ \\ Maria das Dores MENDES SEGUNDO ${ }^{3}$
}

RESUMO: O presente artigo tem como finalidade apresentar a importância da disciplina Teorias da Educação e Formação do Educador no currículo dos cursos de mestrado e doutorado do Programa de Pós-Graduação em Educação da Universidade Estadual do Ceará (PPGE/UECE), cujos estudantes, majoritariamente, são professores provenientes da rede básica dos municípios e estados do Nordeste brasileiro. O estudo em tela é ancorado na perspectiva da ontologia marxiano-lukacsiana, de natureza teórico-bibliográfica, apreendendo o corpus teórico dos estudos de Commenius a Saviani. Asseveramos que os estudos dos clássicos aos contemporâneos contribuem com uma espécie de edifício teórico do programa, fortalecendo as relações entre teoria e prática na formação de educadores, o que, por conseguinte, reverbera em sua práxis.

PALAVRAS-CHAVE: Teorias da educação. Formação do educador. Relação teoria-prática.

RESUMEN: Presente artículo tiene como finalidad presentar la importancia de la disciplina Teorías de la Educación y Formación del Educador en el currículo de los cursos de maestría y doctorado del Programa de Postgrado en Educación de la Universidad Estatal de Ceará (PPGE / UECE), cuyos estudiantes, mayoritariamente, son profesores provenientes de la red básica de los municipios y estados del Nordeste brasileño. El estudio está anclado en la perspectiva de la ontología marxiano-lukacsiana, de naturaleza teórico-bibliográfica,

\footnotetext{
${ }^{1}$ Universidade Estadual do Ceará (UECE), Fortaleza - CE - Brasil. Professora do Programa de Pós-Graduação em Educação. Doutora em Educação Brasileira pela Universidade Federal do Ceará (UFC). Pesquisadora do Instituto de Estudos e Pesquisa do Movimento Operário (IMO) da UECE. ORCID: https://orcid.org/0000-00030070-4123. E-mail: depaularuth@gmail.com.

${ }^{2}$ Universidade Estadual do Ceará (UECE), Fortaleza - CE - Brasil. Professora do PPGE. Doutora em Educação Brasileira pela UFC. Pesquisadora do IMO/UECE. ORCID: https://orcid.org/0000-0001-8760-0380. E-mail: betaneamoraes@gmail.com.

3 Universidade Estadual do Ceará (UECE), Fortaleza - CE - Brasil. Professora do PPGE do Mestrado Acadêmico Intercampi em Educação e Ensino (MAIE). Professora Colaboradora do Programa de Pós-Graduação em Educação Brasileira da UFC. Doutora em Educação Brasileira pela UFC. Pesquisadora do IMO. ORCID: https://orcid.org/0000-0003-2105-3761.E-mail: mariadores.segundo@uece.br.
} 
aprehende el corpus teórico de los estudios de Commenius a Saviani. Además, los estudios de los clásicos a los contemporáneos, contribuyen con una especie de teórico del programa, fortaleciendo las relaciones entre teoría y práctica en la formación de educadores, y por ello, reverberó en su praxis.

PALABRAS CLAVE: Teorías de la educación. Formación del educador. Relación teoríapráctica.

ABSTRACT: The purpose of this article is to present the importance of the discipline Theories of Educating and Teacher Training in the curriculum of the masters and doctorate courses of the Postgraduate Program in Education of the State University of Ceará (PPGE / UECE), whose students, mostly, they are professors from the elementary schools of the municipalities and states of Brazilian Northeast. The study is anchored in the perspective of the Marxian-Lukacsian ontology, of a theoretical-bibliographic nature, it apprehends the theoretical corpus of the studies from Commenius to Saviani. In addition, the studies of classics to contemporaries, contribute with a kind of program theorist,reinforcing the relationships between theory and practice in the training of educators, and therefore, reverberated in their praxis.

KEYWORDS: Theories of education. Educator's training. Theory-Practice relationship.

\section{Introdução}

A disciplina Teorias da Educação e Formação do Educador, do Programa de PósGraduação em Educação da Universidade Estadual do Ceará (PPGE/UECE), foi sendo edificada a partir de $2008^{4}$, no sentido de recuperar a teoria como fundamento da prática educacional, reverberando nos estudantes tanto de mestrado quanto de doutorado uma verdadeira virada teórica e conceitual, uma vez que estes ou não tiveram acesso aos clássicos da teoria da educação ou o tiveram de modo parcial/superficial nas suas graduações, em pedagogia ou em outras licenciaturas ou bacharelados, que o mestrado e o doutorado do PPGE acolhem.

Ministrada no primeiro semestre da Pós-Graduação em Educação, a sua ementa se fundamenta na educação como um complexo mediado pelo trabalho e, nesta perspectiva, aponta os marcos fundamentais do pensamento educacional historicamente produzido, com vistas à compreensão crítica e contextualizada dos paradigmas hoje dominantes no campo da formação do professor, como podemos observar com nitidez nos pressupostos teóricos divididos didaticamente em três grandes eixos, a seguir explicitados.

4 Vale registrar que a professora Susana Jimenez começou a ministrar, neste ano, a disciplina 'Teorias da Educação e Formação de Professores’ no PPGE-UECE, inaugurando, com maestria, este desenho ora em curso.

RIAEE - Revista Ibero-Americana de Estudos em Educação, Araraquara, v. 14, n. 4, p. 2333-2344, out./dez. 2019. e-ISSN: $1982-5587$. 
Com este propósito, no primeiro eixo apresentamos os marcos fundamentais da história do pensamento educacional, revisitando Suchodolski, esclarecendo a querela entre as pedagogias da essência e da existência, evidenciando as rupturas, entrecruzamentos e reedições dela decorrentes. Outrossim, percorremos o caminho de Suchodolski a Saviani, pela mediação de Manacorda, na busca por apreender a configuração das teorias educacionais.

No segundo eixo, iniciamos o estudo dos clássicos, trazendo Commenius (1592-1670), autor que pode ser considerado o pai da pedagogia moderna. A partir dos estudos de Commenius, evidenciamos a reforma da escola, cujo princípio era ensinar tudo a todos para reformar a condição humana. Daí, adentramos no Iluminismo, trazendo a contestação humanista de Rousseau (1712 - 1778), ressaltando que os alunos fazem uma leitura imanente da obra Emilio ou da Educação e Do Contrato Social, a exemplo do modo como procedem com os demais autores, ou seja, recorrendo às suas principais obras.

Percorrendo a linha do tempo, não podemos deixar de analisar o pensador Jean Piaget (1896 - 1980), que se torna o mentor do Construtivismo, com forte influência na transmutação do conhecimento em saber, a partir de sua Epistemologia Genética. Abordamos os estudos do filósofo americano John Dewey (1859 - 1952), o qual alicerça o pragmatismo, destacando a educação para a vida como via direta para democracia. Prosseguimos com os discípulos de Dewey no Brasil, Lourenço Filho (1897 - 1970), Fernando de Azevedo (1894 - 1967) e Anísio Teixeira (1900 - 1971), os quais fundam a escola nova brasileira. Outro importante pensador da educação brasileira presente nesta disciplina é Paulo Freire (1921 - 1997), com a defesa da tese da educação dialógica. Buscamos seguir com suas formulações, desde aquelas sobre a libertação do oprimido até as mais recentes sobre cidadania planetária.

No terceiro eixo, destacamos as teorias educacionais e os fundamentos marxistas para uma educação emancipadora. Para tanto, introduzimos as formulações marxianas sobre educação, contextualizando o trabalho como complexo fundante do ser social, através da rica contribuição de Lukács (1885 - 1971) para o entendimento da relação trabalho-educação.

Ressaltamos, nesse eixo, o pensamento educacional de Gramsci (1891 - 1937), destacando suas elaborações sobre a Escola Unitária. A Psicologia Histórico-Cultural e a Educação também se fazem presentes a partir da base marxista de Vigotski (1896 -1934), Leontiev (1903 -1979) e Luria (1902 - 1977). Ademais, neste eixo, abordamos em linhas gerais o pensamento educacional contemporâneo, no contexto da crise estrutural do capital, tendo Mészáros como referência. Nesse sentido, destacamos os desdobramentos da crise sobre a educação, centrada numa formação do professor sob o primado do neo-pragmatismo e 
do pós-modernismo. Por fim, apresentamos os estudos de Dermerval Saviani (1944) sobre a Pedagogia Histórico-Crítica, a partir da leitura imanente de suas principais obras.

Com efeito, a seleção dos pensadores constantes busca abranger as grandes tendências pedagógicas em âmbito mundial e nacional, situando-os como os responsáveis pelos desdobramentos atuais da educação brasileira.

\section{O Coração da Disciplina: a teoria em nome de uma práxis transformadora}

A disciplina Teorias da Educação e Formação do Educador, conforme viemos apresentando, tem como objetivo apresentar os principais teóricos e pensadores da educação, fortalecendo a ideia de que os professores precisam ter acesso a este complexo categorial, com vistas a compreender o movimento do real em sua totalidade, historicidade e contradições. Para tanto, utiliza-se como fio condutor de análise da categoria trabalho como fundante dos demais complexos sociais, dentre eles, a educação, que detém a condição de categoria universal. Vale assinalar que, no atual contexto do capital em crise estrutural, as diretrizes educacionais são permeadas por concepções e paradigmas pedagógicos que aparentemente parecem inovadores, no entanto, ao serem analisados em sua raiz, consistem mesmo em teorias reeditadas ou reconfiguradas dos pensadores clássicos que são distorcidas e mascaram a realidade.

Nesta direção, buscamos apreender a concepção de homem e sociedade que a norteiam, seus ideais e consequentemente as políticas educacionais que a legitimam, buscando estabelecer contrapontos, tomando a educação como um complexo mediado pelo trabalho e, nesta perspectiva, apontando os marcos fundamentais do pensamento educacional historicamente produzido, com vistas à compreensão crítica e contextualizada dos paradigmas hoje dominantes no campo da formação do professor.

As aulas e os seminários sobre os teóricos da educação são norteados da seguinte forma: inicialmente apresentamos o contexto histórico vivenciado ou testemunhado pelo pensador estudado, em seguida traçamos o percurso de vida de cada autor, do nascimento à sua trajetória acadêmica e profissional, bem como as obras publicadas no decurso de sua démarche histórica. Passado este primeiro momento, procedemos à análise de uma ou duas obras principais do autor, rastreando as categorias centrais, tais como: de essência humana; do conhecimento; da relação indivíduo-sociedade; da relação teoria-prática; da relação objetividade-subjetividade; dos fins sociais da educação; e do lugar do professor no processo educativo. 
Vale ressaltar que tais delineamentos tomam como questão primordial os fundamentos teórico-práticos da educação, entendendo a educação como um dos complexos mais relevantes na formação humana, o qual em conjunto com os demais constitui o mundo dos homens, em sua totalidade. Para tanto, reconhecemos o trabalho como gênese do ser social, fonte inesgotável do devir humano. Nesse sentido, seguimos com Marx e Engels (2005, p. 4445) ao afirmarem que:

Pode-se distinguir os homens dos animais pela consciência, pela religião e tudo o que se quiser. Os próprios homens começam a se distinguir quando iniciam a produção dos seus meios de vida, passo em frente que é consequência de sua organização corporal. Ao produzirem seus meios de existência os homens indiretamente produzem a sua própria vida material.

A ontologia marxiana torna claro para nós que o homem se autoproduz pelo trabalho, sendo este uma atividade vital consciente através da qual se objetiva uma relação eterna e ineliminável do homem com a natureza. Com o trabalho os homens realizam um salto ontológico, efetivando o recuo das barreiras naturais, o que abre possibilidades para o homem constituir-se socialmente. Daí, reconhecemos com base na ontologia marxiano-lukacsiana que o trabalho configura o momento predominante que inaugura a nova esfera do ser, o ser social.

O complexo da educação, como vimos analisando, mantém diante do trabalho uma relação de dependência ontológica, autonomia relativa e determinação recíproca. Com efeito, a educação como complexo fundado a partir do trabalho constitui uma teleologia secundária, na qual a consciência ocupa lugar central. Tal complexo, como práxis, articula teoria e prática, sendo clivado por reflexões conscientes que abrem um vasto campo de possibilidades voltadas à transformação do devir humano. Para Lukács (1979, p. 87),

O trabalho é antes de mais nada, em termos genéticos, o ponto de partida da humanização do homem, do refinamento das suas faculdades, processo do qual não se deve esquecer o domínio sobre si mesmo. Além do mais, o trabalho se apresenta, por um longo tempo, como o único âmbito desse desenvolvimento; todas as demais formas de atividade do homem, ligadas aos diversos valores, só se podem apresentar como autônomas depois que o trabalho atinge um nível relativamente elevado.

Jimenez (2013) tomando por base a ontologia marxiano - lukacsiana, ao situar a educação como complexo fundado pelo trabalho, assinala que:

O trabalho sozinho não foi suficiente para garantir a reprodução do homem porque as necessidades criadas no processo de trabalho foram se 
complexificando e o trabalho foi chamando a cena outros complexos. O conjunto desses complexos é que constitui a chamada práxis, a práxis social.

Ao formular o programa desta disciplina, a professora Susana Jimenez põe em foco a premissa de que não devemos temer a teoria, o que é dito inúmeras vezes por ocasião das defesas de teses e dissertações nas quais participa como orientadora e/ou membro de banca examinadora. Faz todo sentido a defesa intransigente da teoria em sua adequada relação com a prática, uma vez que atravessamos um tempo sombrio em relação aos fundamentos que norteiam a prática dos educadores na contemporaneidade, corolário da pós-modernidade.

Daí asseveramos, no rastro de seu pensamento, que a prática esvaziada de sentido presta um desserviço à classe trabalhadora, tendo em vista a fragilidade conceitual fomentada por teorias que não condizem com uma perspectiva onto-histórica do ser social e que, ao fim e ao cabo, não apontam para a formação do gênero humano, prestando, outrossim, auxílio à reprodução do capital.

Há, é bem verdade, toda uma série de práticas que se propõem a superar as aulas tradicionais da educação escolar, as quais, em nome do contraponto às chamadas aulas enfadonhas e repetitivas, defendem ardorosamente o conhecimento construído pela experiência do próprio aluno, em detrimento do ato de ensinar: função precípua do professor. Diante dos ataques frontais que a educação escolar tem sofrido, o esvaziamento do conteúdo que ilumina a práxis vem ocupando lugar de destaque.

Com efeito, a disciplina Teorias da Educação e Formação do Educador toma assento somando esforços no intuito de soerguer o conhecimento com vistas à formação da classe trabalhadora, uma vez que, dispondo de fundamentos teóricos que revolucionem sua prática, possibilita objetivações humano-genéricas, as quais abrem possibilidades de transformação nas esferas objetiva e subjetiva do ser social.

Entendemos que a teoria, ao ser devidamente articulada à prática, aponta caminhos na contramão de ativismos e teoricismos hoje tão presentes dado o eco da pós-modernidade, em que o pluralismo tem contribuído sobremaneira para uma terra de ninguém, uma vez que, recheada de imediatismo/subjetivismo, nega os clássicos com a insana justificativa de estarem ultrapassados pelo tempo e defende uma prática inócua, visto que a falseabilidade dos argumentos gestados repercute em impedimentos que embaçam a apropriação do real em movimento.

Ao nos referirmos a não temer a teoria, vislumbramos no horizonte a emancipação humana, o que demanda a aproximação do real para além das aparências, com vistas à superação do real, inicialmente como um todo caótico. Assinalamos que a partir de múltiplas 
e complexas mediações podemos examinar e expor os liames onto-históricos que conformam o mundo dos homens.

No decurso desta disciplina buscamos, todavia, orientados pela ontologia marxianolukacsiana, destacar a partir de seus temas centrais a relação que se estabelece entre o indivíduo e o complexo da educação - mais uma vez considerando o trabalho como ato gênese do ser social. Evidenciamos a crise das ciências humano-sociais fazendo um recorte para a problemática da educação, esboçando a questão entre gnosiologia e ontologia na apropriação do real, destacando o subjetivismo e o individualismo como entraves à práxis educativa com vistas à emancipação humana.

No que se refere à relação entre indivíduo e educação, consideramos que este importante complexo social constitui um processo que possibilita uma teia de ricas mediações entre o indivíduo e a história humana. Considerando com Leontiev (1978) que o homem não nasce homem, mas assim se torna, na concretude do real em movimento dialético. Nesse sentido, é oportuno assinalar que os indivíduos com suas consciências constituem a pedra de toque do ato educativo. Lima (2009, p.104-105) apoiada na ontologia marxiano-lukacsiana, no que se refere à relação entre trabalho, educação e reprodução, reconhece que,

Na educação, por ser práxis social, são postas teleologias secundárias, voltadas a influenciar o comportamento de outros sujeitos, visando a realização de determinadas posições teleológicas. Aqui, a teleologia dirigese a outro sujeito (ou vários sujeitos), o qual não é indiferente ao processo. A presença da decisão alternativa em ambos os lados da relação é um importante elemento para a compreensão da especificidade da práxis social e, particularmente, da educação. Nesse sentido, o resultado alcançado pode não coincidir com a intenção original porque, além da presença dos fatores citados em relação às posições teleológicas primárias, na objetivação de posições teleológicas secundárias, a alternativa do indivíduo - alvo da teleologia secundária - também pode ser diferente da finalidade posta.

Afastemos, portanto, a ideia inatista constante da concepção de homem como ser abstrato e isolado, ou de uma natureza natural de homem, presente na perspectiva de Rousseau e Locke, por exemplo; ora considerando o homem como um ser naturalmente bom, sendo a sociedade que o corrompe, ora o homem como lobo do homem. Longe também da concepção de homem como papel blanco, cera virgem, cuja história é escrita pela experiência dos sentidos, tal como advoga a corrente ambientalista/empirista.

Uma vez que o homem é demiurgo de sua história, distanciemo-nos também da compreensão equivocada pela qual se vislumbra que, pelo fato de a educação ser uma ação sobre consciências, seu papel deva ser subsumido, ou seja, dissolver-se sob o reinado das 
consciências como se estas fossem de ordem metafísica, e se sobrepor à objetividade. Vale registrar que o educador pode supor, mas não garantir na totalidade essa ou aquela reação do educando. Toda e qualquer perspectiva que se apoie na unilateralidade, impondo dicotomias na relação entre sujeito-objeto, teoria-prática, espírito-matéria, implica na apreensão fragmentária da realidade objetiva. Como assegura Lukacs (1969, p. 16):

O homem é em si um complexo, no sentido biológico; mas como complexo humano não pode ser decomposto; por isso, se quero compreender os fenômenos sociais, devo considerar a sociedade, desde o princípio, como um complexo de complexos.

Ora, o que é a consciência sem o ser consciente? Nesse sentido, entendemos que o professor joga um papel fundamental na formação do sujeito revolucionário. Reconhecendo com Saviani (2005, p. 13) que a educação é, "o ato de produzir, direta e intencionalmente, em cada indivíduo singular, a humanidade que é produzida historicamente e coletivamente pelo conjunto dos homens", assinalamos, pois, que o ser consciente se humaniza no movimento do real, no qual as esferas ontológicas são ineliminavelmente articuladas e onde os complexos sociais mantém com o trabalho uma relação de dependência ontológica. Desse modo, como nos alerta Alves (2004, p. 06),

[...] aqueles que advogam a onipotência da vontade em termos educacionais, tendem a subestimar o ônus efetivo das determinações da realidade social e, imaginando-se imperadores do real, sucumbem miseravelmente ao peso do próprio mundo, convertendo tudo, ora num simples jogo de quem está no poder (política), ora numa questão de método pedagógico (educação).

As pedagogias hegemônicas, nascidas sob o lema aprender a aprender como contraponto à pedagogia tradicional, situam o ensino em segundo plano, pondo em alto-relevo o aprender naquilo que é significativo para o aluno, deixando, assim, a cargo do aluno a chamada "vontade educativa," divorciando o professor da sua atividade por excelência. Uma vez sendo o ensino distanciado do professor, faz-se necessária uma miríade de categorias para embasar o aprender a aprender - prenhe de "vontade educativa", por exemplo: competências, habilidades, reflexão, experiência, esperança, projetos, etc., as quais nomeiam um conjunto de ideários pedagógicos, que configuram reedições do Escolanovismo. A crise das Ciências Humanas e Sociais, como nos indica Tonet (2018, p. 4),

[... expressa] o caráter epistemológico da interpretação, onde toda a problemática da cientificidade é vista do ângulo do sujeito, cabendo sempre a ele decidir sobre as causas, o sentido e as soluções do problema. A 
realidade objetiva não aparece como um momento, também ele essencial que compõe o complexo momento da totalidade social que é responsável por todos os fenômenos sociais.

$\mathrm{Na}$ contramão desta perspectiva, reiteramos que a disciplina Teorias da Educação e Formação do Educador tem por objetivos: refletir sobre as complexas mediações que articulam a teoria (educacional) e a prática (docente) em sua ineliminável conexão com o processo de reprodução social; discutir os pressupostos pedagógicos e sócio-filosóficos que distinguem ou interconectam as principais teorias da educação produzidas no curso da história; oferecer elementos de compreensão dos determinantes onto-históricos das teorias sócio-educacionais vigentes e suas implicações no espaço da formação docente.

Compreendemos que a adequada relação entre teoria e prática na formação docente implica uma aproximação do real, de modo a realizar um exame crítico ante à dissociação cada vez mais nítida entre o discurso e a realidade objetiva. Enquanto o real em movimento avança no sentido da degenerescência da vida humana, as soluções apontam para um dever ser inócuo, no qual tanto a ajuda mútua como a solidariedade são fortalecidas por um apelo moralizante, tendo como horizonte o interesse pelo bem comum.

No entanto, envolta em contradições, a sociabilidade regida pelo capital é encoberta por um denso véu ideológico no qual o ser se move numa perspectiva cada vez mais individualista em oposição a um dever ser solidário. Daí esbarramos numa visão idealista de formação humana, embarreirando a objetividade, ou seja, quanto mais se caminha em rumos contrários à transformação da realidade objetiva, mais se reforça, via discurso, a necessidade de mudar a realidade. Ora, o que a teoria tem a ver com isso?

Retomemos duas passagens do livro Escola e Democracia quando Saviani (2012, p. 48), ao estabelecer uma crítica à Escola Nova, assinala que: "quando mais se falou em democracia no interior da escola, menos democrática foi a escola; e, quando menos se falou em democracia, mais a escola esteve articulada com a construção de uma ordem democrática”. Considerando as reedições do ideário da Escola Nova, presentes na escola nos dias atuais, observamos que a visão idealista aponta para um beco sem saída, uma vez que não busca atingir o problema em sua raiz, ou seja, a própria existência do capital.

Nesse sentido, o discurso escamoteia a realidade, produzindo reflexões que não possibilitam uma práxis que desmonte o que está posto. Tomemos como exemplo a segunda passagem, destacada por Saviani (2012, p. 48):

[...] o abandono da busca de igualdade é justificado em nome da democracia e é nesse sentido também que se introduzem no interior da escola 
procedimentos ditos democráticos. E hoje nós sabemos, com certa tranquilidade, já, a quem serviu essa democracia e quem se beneficiou dela, quem vivenciou esses procedimentos democráticos e essa vivência democrática no interior das escolas novas.

A resposta ao questionamento lançado acima diz respeito à importância do conteúdo a ser ministrado, o qual, respaldado por seu devido rigor teórico e metodológico, contribui para a formação de um agir, pensar e sentir concernentes à formação humana integral, onde o homem pode vir a, efetivamente, apropriar-se das aquisições da cultura humana ou, como concebe Leontiev (1978, p. 283), em que "cada homem, cada povo tenha a possibilidade prática de tomar o caminho de um desenvolvimento que nada entrave".

Diante do exposto, asseveramos que a ação educativa sobre as consciências joga um relevante papel na formação de uma consciência revolucionária ou reacionária, o que implica diretamente em uma educação alinhada ao socialismo ou à barbárie. Nesse sentido, seguimos assinalando que somamos nossos esforços aos da classe trabalhadora no sentido de suprimir radicalmente toda fonte de exploração do homem pelo homem e, assim, vislumbrar o alcance do gênero humano em sua forma plena, tanto quantitativa quanto qualitativamente.

\section{Considerações Finais}

Nossa luta, por fim, justifica-se em reconhecer que a classe trabalhadora necessita de uma educação que lhe possibilite uma concepção de mundo radicalmente diferente e superior àquela idealizada e consolidada pela sociedade burguesa. A educação burguesa tradicional, mesmo na forma mais elevada em que possa ser apresentada, ainda constitui um impeditivo à emancipação humana, daí, asseverarmos que a educação destinada à classe trabalhadora tem de ser revolucionária.

Consideramos que a educação é um complexo importante para a emancipação humana, uma vez que é entre consciências que a instrumentalização, via conhecimento, é aplicada. Por meio de um conjunto coeso entre teoria e prática, decisões, sentimentos e pensamentos podem ser transformados, tornando-se qualitativamente superiores. Daí asseveramos que as escolhas entre alternativas engendradas pelo ato de ensinar podem vislumbrar o horizonte do gênero humano.

Reconhecemos que tais escolhas são socialmente determinadas, isto é, as condições de vida e trabalho se interpõem e consistem em uma teia de ações que conectam objetividade e subjetividade. Daí, as respostas elaboradas pelo indivíduo estão intimamente vinculadas às 
necessidades e possibilidades postas pelas circunstâncias de sua existência situada na realidade objetiva.

Chamamos atenção para a dialética presente na busca que o indivíduo realiza com vistas a transpor a barreira da pura particularidade, aspirando à elevação como ser genérico. Pessoa e gênero se conectam no sentido de superar a mudez, articulando-se à consciência do vínculo real com a própria generidade. Com efeito, manifesta-se na consciência um conflito gestado como negação às contradições existentes entre indivíduo e sociedade (COSTA, 2007).

Reafirmamos que a educação é um complexo social por meio do qual se realiza a mediação entre individuação e generidade, sendo essencial para a reprodução do gênero humano. O caráter social da educação chama para si categorias pertinentes à sociabilidade humana, as quais, diferentemente das categorias existentes na esfera biológica, só podem ser explicadas em termos sociais. Com efeito, ainda que a base biológica seja ineliminável, o momento predominante na concretude dos complexos sociais não configura em forças motrizes naturais, mas concernentes à esfera do ser social.

Diante do exposto, asseveramos que a reprodução social das individualidades tem implicações na tomada de decisão diante das demandas postas no mundo dos homens. Tal processo dialético ocorre em um campo valorativo, no qual o presente é avaliado tendo em vista as possibilidades que surgem em meio a ideias e projetos sociais que apontam o devir. Portanto, mais uma vez enfatizamos o papel da educação na formação humana, por conseguinte nas alternativas escolhidas pelos indivíduos, uma vez que estas denotam identificações que coadunam com o rumo que se propõem a dar à sua existência em uma dada sociabilidade.

\section{REFERÊNCIAS}

ALVES, A. L. A Determinação onto-societária do educar ou para uma crítica da vontade educativa. Verinotio - Revista On-line de Educação e Ciências Humanas. n. 1, Ano I, out. 2004.

COSTA, G. Indivíduo e Sociedade. Maceió. UFAL, 2007.

JIMENEZ, S. A educação sobre quatro pilares: uma nova pedagogia em favor de uma velha ordem? - Videoconferência. Palestra realizada durante o VIII Colóquio de Formação de Professores e Docência Universitária que ocorreu na tarde do dia 7 de junho de 2013 na sala Papirus da Faculdade de Educação da Universidade de Brasília. Promoção: Grupo de Estudos e Pesquisa sobre Docência Universitária e Inovações Pedagógicas e Grupo de Estudos e Pesquisa sobre Marxismo e Formação do Educador - MarxEduca. Gravação e edição: Efrain 
Maciel e Silva. Publicada em 8 jun. 2013. Disponível em: http://boletimef.org. Acesso em: 29 out. 2018.

LEONTIEV, A. O Desenvolvimento do Psiquismo. Lisboa. Livros Horizonte, 1978.

LIMA, M. Trabalho, Reprodução Social e Educação em Lukács. 2009. 127f., Dissertação de Mestrado - UECE, Fortaleza, 2009.

LUKÁCS, G. Conversando com Lukács. Trad. Giseh Vianna Konder. São Paulo: Instituto Lukács, 2014.

LUKÁCS, G. Ontologia do ser social: Os princípios ontológicos fundamentais de Marx. Trad. Carlos Nelson Coutinho. São Paulo, Ciências Humanas, 1979.

MARX, K.; ENGELS, F. A ideologia alemã. Trad. Frank Muller. São Paulo: Martin Claret, 2005

SAVIANI, D. Pedagogia histórico-crítica: primeiras aproximações. 9. ed. Campinas. Autores Associados, 2005.

SAVIANI, D. Escola e Democracia. São Paulo. Autores Associados, 2012.

TONET, I. A crise das ciências sociais. Disponível em:

https://observatorioveiasabertas.com.br/wp-

content/uploads/2018/02/a_crise_das_ciencias_sociais.pdf. Acesso em: 29 nov. 2018

\section{Como referenciar este artigo}

PAULA, R. de; MORAES, B.; MENDES SEGUNDO, M. das D. Teorias da educação e formação do educador: contra o esvaziamento do conteúdo e a favor de uma práxis revolucionária. Revista Ibero-Americana de Estudos em Educação, Araraquara, v. 14, n. 4, p. 2333-2344, out./dez. 2019. e-ISSN: 1982-5587. DOI: https://doi.org/10.21723/riaee.v14i4.12044

Submetido em: 25//02/2019

Revisões requeridas: 10/04/2019

Aprovado em: 17/07/2019

Publicado em: 02/09/2019 